\title{
Chordal "translocation" for functional mitral regurgitation with severe valve tenting: An effort to preserve left ventricular structure and function
}

Masahira Fukuoka, MD, Michihito Nonaka, MD, Shinji Masuyama, MD, Takeshi Shimamoto, MD, Keiichi Tambara, MD, PhD, Hajime Yoshida, ME, Tadashi Ikeda, MD, PhD, and Masashi Komeda, MD, PhD

From the Department of Cardiovascular Surgery, Graduate School of Medicine, Kyoto University, Kyoto, Japan.

Read at the Eighty-sixth Annual Meeting of The American Association for Thoracic Surgery, Philadelphia, Pa, April 29-May 3, 2006.

Received for publication May 1, 2006; revisions received Oct 19, 2006; accepted for publication Oct 26, 2006.

Address for reprints: Masashi Komeda, MD, $\mathrm{PhD}$, Department of Cardiovascular Surgery, Graduate School of Medicine, Kyoto University, 54 Shogoin kawahara-cho, Sakyo-ku, Kyoto, Japan 606-8507 (E-mail: komelab@ kuhp.kyoto-u.ac.jp).

J Thorac Cardiovasc Surg 2007;133:1004-11 $0022-5223 / \$ 32.00$

Copyright (๑) 2007 by The American Association for Thoracic Surgery

doi:10.1016/j.jtcvs.2006.10.063
Objective: The chordal cutting method is performed for mitral valve tenting in functional mitral regurgitation, such as ischemic mitral regurgitation. However, the method may interfere with the mitral valvular-ventricular continuity. To maintain the continuity and the natural force direction between the papillary muscles and the mitral annulus after chordal cutting, we developed "translocation" of the secondary chordae tendineae.

Methods: Six mongrel dogs had sonomicrometry crystal markers implanted in the left ventricle, mitral annulus, and papillary muscle tips. After the secondary chordae tendineae of the anterior mitral leaflet from each papillary muscle were resected, each papillary muscle tip was connected to the mid-anterior mitral annulus with 4-0 polypropylene sutures, and then the sutures were taken out of the left atrium to control the chordal tension. The condition under which the artificial chordae were released was defined as "redundant." The chordal tension of $15 \mathrm{~g}$ of weight was defined as "taut," whereas the tension for 2-mm chordal shortening after "taut" was defined as "tight." After the dogs were weaned from cardiopulmonary bypass, hemodynamic and 3-dimensional data were acquired under the condition of "redundant," and then "taut," "tight," and "redundant."

Results: End-systolic elastance increased from $1.81 \pm 0.24 \mathrm{~mm} \mathrm{Hg} / \mathrm{mL}$ to $2.69 \pm$ $0.89 \mathrm{~mm} \mathrm{Hg} / \mathrm{mL}(P=.015)$ between "redundant" and "taut," and this was maintained between "taut" and "tight." However, preload recruitable stroke work increased from $41.3 \pm 12.0 \mathrm{~mm} \mathrm{Hg}$ to $58.1 \pm 19.7 \mathrm{~mm} \mathrm{Hg}(P=.005)$ between "redundant" and "taut," and was reduced to $51.7 \pm 22.9 \mathrm{~mm} \mathrm{Hg}(P=.037)$ between "taut" and "tight."

Conclusion: "Translocation" of the secondary chordae tendineae after chordal cutting improved left ventricular systolic function compared with simple chordal cutting.

I schemic cardiomyopathy (ICM) after myocardial infarction accompanies remodeling of the left ventricle (LV) and papillary muscles (PMs). ${ }^{1,2}$ Morphologic changes on the LV, displacement of the PM tips, and dilatation of the mitral annulus (MA) lead to mitral valve tethering and tenting ${ }^{1-3}$ (Figure 1). In addition, mitral valve tenting creates a smaller than normal mitral valve coaptation zone. Therefore, many patients with ICM have functional ischemic mitral regurgitation (MR). ${ }^{2-4}$ Because congestive heart failure caused by ICM with ischemic MR is refractory, it often requires surgical treatment. ${ }^{5-7}$ Mitral valve annuloplasty using an undersized ring can be performed to reduce the MA size and the anteriorposterior mitral annular dimension ("cinching"), thereby improving the coaptation zone. ${ }^{8-10}$ However, it is difficult to control MR in the long term by mitral valve annuloplasty alone in patients with severe valve tenting with a coaptation depth of 


$$
\begin{aligned}
& \text { Abbreviations and Acronyms } \\
& \begin{aligned}
\mathrm{AL} & =\text { anterior leaflet } \\
\mathrm{CPB} & =\text { cardiopulmonary bypass } \\
\mathrm{CT} & =\text { chordae tendineae } \\
\mathrm{Ees} & =\text { end-systolic elastance } \\
\mathrm{FS} & =\text { fractional shortening } \\
\mathrm{ICM} & =\text { ischemic cardiomyopathy } \\
\mathrm{LA} & =\text { left atrium } \\
\mathrm{LV} & =\text { left ventricle } \\
\mathrm{MA} & =\text { mitral annulus } \\
\mathrm{MR} & =\text { mitral regurgitation } \\
\mathrm{MVR} & =\text { mitral valve replacement } \\
\mathrm{PM} & =\text { papillary muscle } \\
\mathrm{PRSW} & =\text { preload recruitable stroke work }
\end{aligned}
\end{aligned}
$$

more than $10 \mathrm{~mm} .^{5,6,11-13}$ A number of investigators reported that mitral valve replacement (MVR) had been used for patients with severe valve tenting ${ }^{11,14,15}$ because residual MR deteriorated the prognosis of patients with ICM. $^{7,11,16,17}$

Currently, the chordal cutting method is conducted in patients with ischemic MR associated with severe valve tenting. ${ }^{18}$ The method improves the coaptation zone and valve tenting by resecting "secondary" (ie, strut) chordae tendineae (CT), which are related to valve tenting, ${ }^{19-22}$ and subsequently normalizing the 3-dimensional shape of the anterior leaflet (AL) (ie, slightly curved shape toward the left atrium [LA]). However, the secondary CT are anatomically thick components that maintain the mitral valvularventricular continuity, which plays an important role in the function of the $\mathrm{LV}^{23}$ Therefore, the method may reduce the tenting and regurgitation of the mitral valve at the sacrifice of the LV systolic geometry and/or potential function. ${ }^{21,22,24}$

The secondary CT are attached to the AL on the ventricular side, and the anatomic direction runs toward the midanterior MA (Figure 2). Thus, the force direction should travel from the PM tip through the AL to the mid-anterior MA. By creating the artificial CT after chordal cutting, we developed a novel surgical solution in which the force between the MA and the PM was preserved, without causing any distortion in the AL geometry, by connecting the mid-anterior MA and the PM tips; the direction of the force was anatomically identical or similar to the natural mitral valvular-ventricular continuity (Figures 1 and 2). We named it chordal "translocation" because the distal ends of the secondary CT are detached from the AL and extended to the mid-anterior MA (Figure 1).

The study may also be informative on the physiology of secondary CT.

\section{Materials and Methods}

The study protocol was approved by the Kyoto University Ethics Committee for Animal Research. All animals received humane care in compliance with the guidelines in the "Principles of Laboratory Animal Care," formulated by the National Society for Medical Research, and the "Guide for the Care and Use of Laboratory Animals," prepared by the Institute of Laboratory Animal Resources, National Research Council, and published by the National Academy Press (revised 1996).

\section{Surgical Preparation}

Six mongrel dogs $(17.5 \pm 0.8 \mathrm{~kg})$ were premedicated with ketamine hydrochloride ( $20 \mathrm{mg} / \mathrm{kg}$ intramuscularly), and general anesthesia was induced with sodium pentobarbital $(15 \mathrm{mg} / \mathrm{kg}$ intravenously). Anesthesia was maintained after endotracheal intubation with oxygen and isoflurane $(0.5 \%-1.5 \%)$. Dogs were
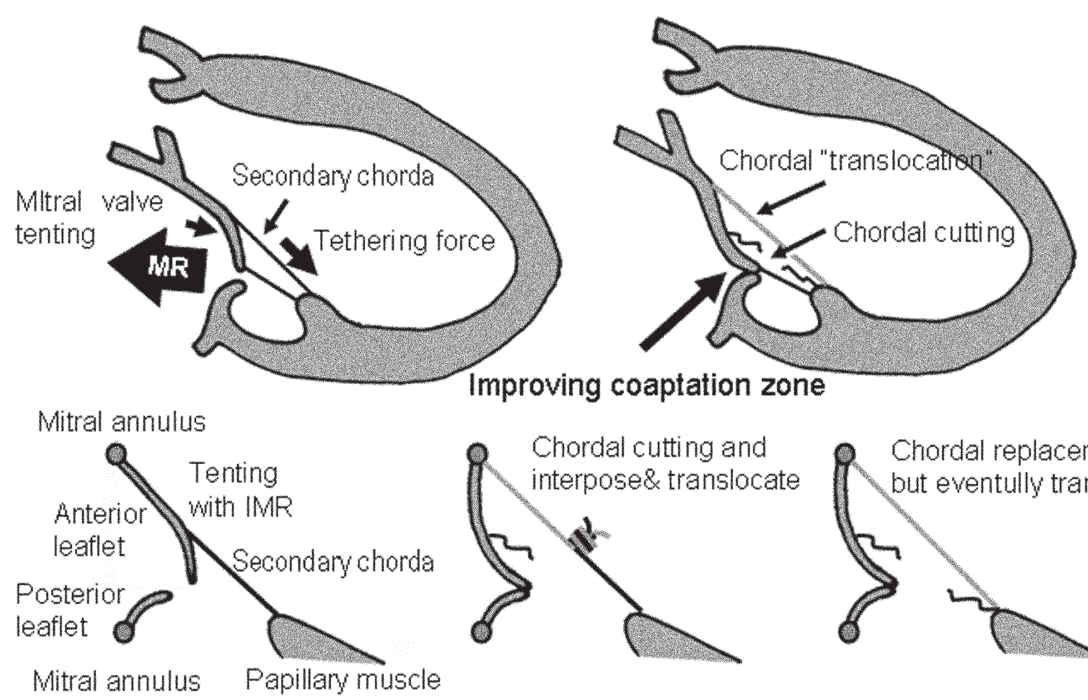

Figure 1. Mitral valve tenting and chordal "translocation." The secondary CT are attached to the central $A L$, and the anatomic direction runs toward the mid-anterior MA. Chordal cutting improves the coaptation zone by normalizing the shape of the $\mathrm{AL}$ owing to cutting the secondary CT, which are related to valve tethering. However, valvular-ventricular continuity is cut too. Our method was that the original and terminal points of the continuity were located in the same place without creating distortion in the AL geometry by connecting with the artificial CT after chordal cutting. We named it chordal "translocation" because the distal ends of the secondary CT are detached from the $A L$ and extended to the mid-anterior MA. MR, mitral regurgitation; IMR, ischemic mitral regurgitation. 


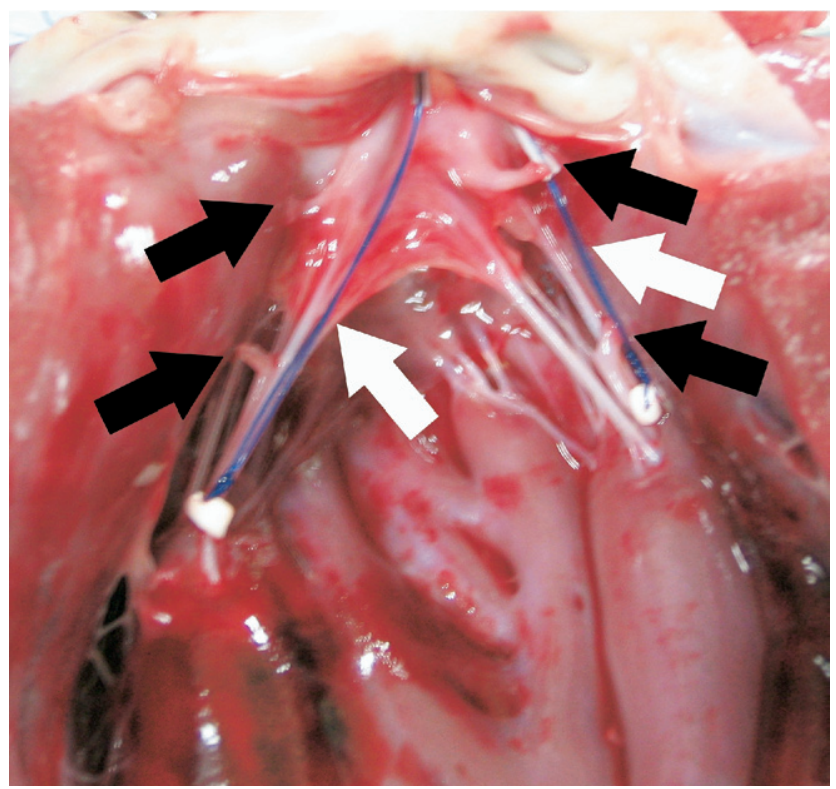

Figure 2. Secondary chordae and operation schema. Ventricular side: secondary chordae after cutting (black arrow); artificial chordae (white arrow) with 4-0 polypropylene sutures between the mid-anterior MA and each PM tip. MA, mitral annulus; PM, papillary muscle.

placed in the right lateral decubitus position, and a left anterior thoracotomy was made through the fifth intercostal space. The pericardium was opened, and the heart was suspended in a cradle. Two crystal markers $2.3 \mathrm{~mm}$ in diameter (Sonometrics Corp, London, Ontario, Canada) were inserted in the subendocardium, defining the anterior and inferior walls at the equator, and a single crystal marker was inserted at the LV apex. The anterior point was identified as the proximal junction between the left anterior descending branch and the first diagonal branch. The inferior point was the left side of the posterior descending branch at the same equator of the anterior point. The crystal markers were placed on the obturator of a plastic sheath and inserted through a stab wound on the epicardial surface. Then the obturator to lead the crystals was advanced into the subendocardium and withdrawn, leaving the crystals in place. A rubber catheter, used as an inferior vena cava occluder, was placed around the inferior vena cava to provide transient preload reduction. During cardiopulmonary bypass (CPB), after cardioplegic arrest and through a left atriotomy, 4 crystal markers were sutured around the circumference of the MA at mid-anterior, mid-posterior, anterior commissure, and posterior commissure in the LA. The 2 largest CT from each PM inserted into the AL were identified as the secondary CT (Figure 2). They were carefully resected, and 2 crystal markers were sutured on each PM tip near their origin. For the artificial CT, the U stay of 4-0 polypropylene was placed at the origin of the secondary CT of the anterior and posterior PMs. Then, 2 plastic catheters $0.95 \mathrm{~mm}$ in diameter were inserted through the mid-anterior MA from the $\mathrm{LA}$ to the $\mathrm{LV}$, and 2 rubber catheters $1.25 \mathrm{~mm}$ in diameter were connected to the plastic catheters. These were fixed with a 5-0 silk



Figure 3. Location of the crystal array in the LV. Sonomicrometer crystals $(2.3 \mathrm{~mm}$ ) (filled circles). APM, anterior papillary muscle; $P P M$, posterior papillary muscle.

suture on the annulus. The distance between each catheter was 3 $\mathrm{mm}$, and the catheter length was $10 \mathrm{~mm}$. Polypropylene sutures from the PMs were inserted through the plastic and rubber catheters from the LV to smoothly move the polypropylene sutures (Figures 2 and 3). The LA was subsequently closed, and polypropylene sutures as the artificial CT with the rubber catheters were taken out from the LA to control the chordal tension. The animals were weaned from CPB, and epicardial color Doppler echocardiography confirmed normal leaflet motion and valvular competence. A micromanometer-tipped catheter (Millar MPC-500, Millar Instruments, Inc, Houston, Tex), used to monitor LV pressure, and a $6 \mathrm{~F}$ conductance catheter (2S-RH6DA-116, Alpha Medical Instruments, Inc, Mission Viejo, Calif), used to monitor the LV volume, were inserted through the LV apex.

\section{Experimental Protocol}

After the dogs were weaned from $\mathrm{CPB}$, atrial pacing was performed at 100 beats/min with a temporary pacemaker. Inotropic agents were not used during weaning from $\mathrm{CPB}$ and when controlling the bleeding from the incision. Dogs were studied with the chest open in the right lateral decubitus position; maintenance anesthesia was continued with isoflurane $(0.5 \%-1.5 \%)$. During hemodynamic and 3-dimensional marker data acquisition, ventila- 
tion was briefly arrested at end expiration to prevent respiratory variation.

We controlled the chordal tension of the artificial CT during the procedure in the following manner. First, we set the chordal tension of the artificial CT free, and the condition was described as "redundant 1." Then, the artificial CT were pulled from the anterior and posterior PM tips and fixed with the rubber catheters so that the chordal tension of the artificial CT was $15 \mathrm{~g}$ in end diastole. Polypropylene sutures were pulled through a pulley by gravity. This condition was described as "taut." After that, the artificial CT were pulled another $2 \mathrm{~mm}$ exactly at the clamp position and fixed. This condition was described as "tight." Finally, the artificial CT were removed. This condition was described as "redundant 2." Data acquisition of hemodynamics and 3-dimensional markers were performed before and after occluding the inferior vena cava with occluder.

\section{Data Acquisition}

Cardiac hemodynamics. Hemodynamic parameters consisted of LV end-systolic pressure, LV end-diastolic pressure, maximum positive rate of change of the LV pressure, minimum negative rate of change of the LV pressure, tau, stroke volume, and cardiac output. The heart rate was set to 100 beats/min by atrial pacing. Finally, end-systolic elastance (Ees) and preload recruitable stroke work (PRSW) were calculated to assess global LV systolic function. Ees and PRSW were calculated for 8 consecutive beats along the mid-slope of the end-systolic pressure-volume relation curve.

Sonomicrometry crystals. Four crystal markers (4-7) were arrayed around the MA, 3 crystal markers (1-3) were placed on the anterior and inferior walls and the apex, and 2 crystal markers ( 8 and 9) were positioned on the tips of the anterior and posterior PMs (Figure 1). The distance between each crystal marker was measured with SonoSOFT software (Sonometrics Corp). The length of the artificial CT was confirmed by measuring the distance between the mid-anterior MA (6) and the anterior and posterior PMs (8 and 9).

The chordal tension of the artificial CT was controlled with polypropylene sutures through the LA from the outside, and the distance-reduction (millimeters) was defined as the reduction of the distance at end diastole between the mid-anterior MA and each PM tip during the conditions of "taut," "tight," and "redundant 2," compared with that during the condition of "redundant 1" (control). The distancereductions were calculated for anterior and posterior sutures, respectively.

The dimension of the LV long axis was determined as the average of the distances between 4 crystal markers around the MA and the crystal marker at the apex. In addition, the dimension of the LV short axis was measured as the distance between the crystal markers in the anterior and inferior walls at the equator (2 and 3); this dimension in end diastole was defined as the LV diastolic dimension. Fractional shortening (FS) was calculated from the end-diastolic and end-systolic dimensions.

\section{Statistical Analysis}

All statistical analyses were performed with StatView software, version 5.0 (SAS Institute, Cary, NC). The data were expressed as mean \pm standard deviation, and comparisons between each condition were performed with the paired $t$ test.

\section{Results}

The aortic crossclamp time was $112.3 \pm 18.3$ minutes. In all 6 animals, it was confirmed by necropsy that crystal markers were correctly placed and that the secondary CT were successfully resected without causing any damage to the primary CT or the anterior mitral valve leaflet. Color Doppler echocardiography revealed no obvious MR after secondary chordal cutting and traction of the artificial CT.

\section{Hemodynamics}

Hemodynamic data for the 4 conditions, "redundant 1," "taut," "tight," and "redundant 2," are listed in Table 1. No significant differences in the LV end-systolic pressure, LV end-diastolic pressure, end-diastolic volume, $\mathrm{LV} \mathrm{dP} / \mathrm{dt}$, LV-dP/dt, or tau were observed between the 4 conditions.

Although the stroke volume and cardiac output increased from $24.4 \pm 5.8 \mathrm{~mL}$ to $28.6 \pm 8.6 \mathrm{~mL}(P=.015)$ and from $2.5 \pm 0.5 \mathrm{~L} / \mathrm{min}$ to $2.9 \pm 0.9 \mathrm{~L} / \mathrm{min}(P=.042)$ between "redundant 1 " and "taut," they did not significantly decrease between "taut" and "redundant 2." In addition, there was no difference between "redundant 1" and "tight."

\section{End-systolic Elastance and Preload Recruitable Stroke Work}

Ees increased from $1.81 \pm 0.24 \mathrm{~mm} \mathrm{Hg} / \mathrm{mL}$ to $2.69 \pm 0.89$ $\mathrm{mm} \mathrm{Hg} / \mathrm{mL}(P=.015)$ between "redundant 1 " and "taut," and this was maintained between "taut" and "tight." Ees significantly diminished to almost the same level during "redundant 1" between "tight" and "redundant 2" (Table 1). However, PRSW increased from $41.3 \pm 12.0 \mathrm{~mm} \mathrm{Hg}$ to $58.1 \pm 19.7 \mathrm{~mm} \mathrm{Hg}$ between "redundant 1" and "taut" (Table 1), and was reduced to $51.7 \pm 22.9 \mathrm{~mm} \mathrm{Hg}(P=$ .037) between "taut" and "tight."

\section{Sonomicrometry Crystals}

The distance-reductions during each condition ("taut," "tight," and "redundant 2") are shown in Table 2.

The diastolic dimension and the degree of FS along the LV long and short axes observed by sonomicrometry for each condition are listed in Table 3.

Although the LV diastolic dimension increased between "redundant 1" and "taut," it did not significantly decline after releasing the artificial CT. The FS along the short axis during "taut" $(12.2 \% \pm 3.7 \%)$ and "tight" $(12.0 \% \pm 3.9 \%)$ 
TABLE 1. Hemodynamics

\begin{tabular}{|c|c|c|c|c|c|c|c|c|}
\hline Hemodynamics & Redundant 1 & Taut & $P 1$ vs $R 1$ & $P 2$ vs $R 2$ & Tight & P3 vs R1 & $P 4$ vs $R 2$ & Redundant 2 \\
\hline Heart rate (beats/min) & 100 & 100 & & & 100 & & & 100 \\
\hline $\mathrm{ESP}(\mathrm{mm} \mathrm{Hg})$ & $60.2 \pm 7.8$ & $64.6 \pm 5.9$ & 0.08 & 0.18 & $62.7 \pm 12.3$ & 0.27 & 0.50 & $62.7 \pm 7.9$ \\
\hline $\mathrm{EDP}(\mathrm{mm} \mathrm{Hg})$ & $8.8 \pm 5.7$ & $9.0 \pm 6.1$ & 0.44 & 0.44 & $8.3 \pm 6.2$ & 0.33 & 0.26 & $9.1 \pm 6.6$ \\
\hline EDV $(\mathrm{mL})$ & $55.1 \pm 5.4$ & $60.2 \pm 10.9$ & 0.17 & 0.12 & $53.7 \pm 10.5$ & 0.31 & 0.38 & $54.8 \pm 6.4$ \\
\hline $\mathrm{dP} / \mathrm{dtmax}(\mathrm{mm} \mathrm{Hg} / \mathrm{s})$ & $1117 \pm 235$ & $1312 \pm 300$ & 0.06 & 0.16 & $1231 \pm 332$ & 0.13 & 0.33 & $1179 \pm 236$ \\
\hline$-\mathrm{dP} / \mathrm{dtmin}(\mathrm{mm} \mathrm{Hg} / \mathrm{s})$ & $685 \pm 71.4$ & $751 \pm 147$ & 0.16 & 0.12 & $703 \pm 172$ & 0.38 & 0.33 & $684 \pm 109$ \\
\hline Tau & $46.1 \pm 15.5$ & $41.3 \pm 17.6$ & 0.24 & 0.21 & $45.2 \pm 24.9$ & 0.45 & 0.41 & $43.8 \pm 13.9$ \\
\hline SV $(m L)$ & $24.4 \pm 5.8$ & $28.6 \pm 8.6$ & *0.015 & 0.065 & $26.8 \pm 9.2$ & 0.12 & 0.36 & $26.2 \pm 6.4$ \\
\hline CO (L/min) & $2.5 \pm 0.5$ & $2.9 \pm 0.9$ & $*^{*} 0.042$ & 0.053 & $2.7 \pm 0.9$ & 0.20 & 0.34 & $2.6 \pm 0.6$ \\
\hline Ees $(\mathrm{mm} \mathrm{Hg} / \mathrm{mL})$ & $1.81 \pm 0.24$ & $2.69 \pm 0.87$ & ${ }^{*} 0.015$ & ${ }^{*} 0.011$ & $2.55 \pm 0.86$ & ${ }^{*} 0.029$ & *0.018 & $1.66 \pm 0.34$ \\
\hline PRSW (mm Hg) & $41.3 \pm 12.0$ & $58.1 \pm 19.7$ & $*^{*} 0.005$ & ${ }^{*} 0.013$ & $51.7 \pm 22.9$ & 0.08 & 0.09 & $40.4 \pm 9.9$ \\
\hline
\end{tabular}

Data shown as mean $\pm S D$. $E S P$, end-systolic pressure, $E D P$, end-diastolic pressure; $E D V$, end-diastolic volume; $d P / d t m a x$, maximum positive rate of change of left ventricular (LV) pressure; - dP/dtmin, minimum negative rate of change of left ventricular (LV) pressure; SV, stroke volume; CO, cardiac output; Ees, End-systolic elastance; $P R S W$, Preload recruitable stroke work; $R 1$, redundant 1 ; $R 2$, redundant $2 . * P 1,{ }^{*} P 3 \leqq 0.05$ vs redundant 1 , t-test for paired observations. ${ }^{*} P 2,{ }^{*} P 4 \leqq 0.05$ vs redundant 2 , t-test for paired observations.

was higher compared with "redundant 1 " $(10.1 \% \pm 2.9 \%)$ $(P=.011$ vs "taut," $P=.026$ vs "tight"). There were no differences in the dimension of the long axis between "redundant 1" and "taut." The dimension of the LV long axis was reduced from $57.3 \pm 5.9 \mathrm{~mm}$ to $56.7 \pm 5.9 \mathrm{~mm}$ between "taut" and "tight" $(P=.024)$. This effect was presented by the significant reduction of the dimensions between the apex and the posterior commissure (1-5) and between the apex and the mid-anterior MA (1-6). The FS along the long axis increased from $8.1 \% \pm 1.6 \%$ to $9.2 \% \pm$ $2.0 \%(P=.017)$ between "redundant 1 " and "taut."

\section{Discussion}

The mitral subvalvular apparatus is composed of the PMs and 2 major sets of CT (ie, primary and secondary). The primary CT are attached to the free margin of the valve leaflet, whereas the secondary $\mathrm{CT}$ are thicker than the primary CT and attached to the ventricular side of the valve leaflet in the transition area between the rough and smooth zones. The subvalvular structure has 2 roles: preventing leaflet prolapse and maintaining LV function. ${ }^{23,25}$

The importance of continuity between the MA and the PMs in LV systolic function is recognized as valvularventricular interactions. The validity of this concept has

TABLE 2. $\triangle$ distance-reduction between mid-anterior MA and each PM tip by chordal tension

\begin{tabular}{lcccr}
\hline & Crystal number & taut & tight & \multicolumn{1}{c}{ redundant 2 } \\
\hline AMA-APM & $6-8(\mathrm{~mm})$ & $2.2 \pm 0.6$ & $3.9 \pm 0.9$ & $0.0 \pm 0.3$ \\
AMA-PPM & $6-9(\mathrm{~mm})$ & $1.6 \pm 0.8$ & $3.3 \pm 0.3$ & $-0.2 \pm 0.4$ \\
\hline
\end{tabular}

$\triangle$ Distance-reduction, Distance (AMA-each PM tip) during redundant 1 distance during taut, tight, and redundant 2; $M A$, mitral annulus; $P M$, papillary muscle; $A M A-A P M$, mid-anterior mitral annulus-anterior papillary muscle; $A M A-P P M$, mid-anterior mitral annulus-posterior papillary muscle. been shown in studies in which preservation of the CT during MVR resulted in better LV function and prognosis. ${ }^{26-28}$ Although the importance of CT preservation in improving LV contractility after valve replacement has become widely accepted, the roles of primary or secondary CT have only recently been studied in detail. ${ }^{23}$ For example, LV function deteriorated (eg, PRSW and Ees) after cutting the secondary CT in a study on sheep. ${ }^{24,29}$

Komeda $^{30}$ reported that mitral chordal reconstruction with the oblique technique was effective for LV function during MVR. However, Komeda's aim was to improve LV function after all CT were resected during MVR, and this technique was not a reconstruction following the anatomic direction of the anterior secondary CT. Our study showed that the secondary CT were physiologically important for LV function by demonstrating that "translocation" of the anterior secondary $\mathrm{CT}$ in a native direction improved LV function after chordal cutting while preserving the primary CT.

In the acute study, experimental results are influenced by the condition of the animal model. However, in this study we developed a model that is relatively free from such problems. First, we confirmed a stable baseline condition of the heart by measuring the "redundant" condition (ie, condition after chordal cutting). Then, we studied the additive effect of the chordal "translocation" by comparing with the baseline (ie, redundant condition). Finally, we studied the effect caused by removal of "translocation." To note, LV function was almost similar in the first and the last serial measurements.

The level of anesthesia was unchanged, and drugs that influence LV function were not administered. We therefore believe that the animal model precisely detected the influence of chordal tension. 
TABLE 3. A comparison of diastolic length and fractional shortening along the long axis and short axis assessed by sonomicrometry in 6 dogs

\begin{tabular}{lcccccccc}
\hline & redundant 1 & taut & $\boldsymbol{P 1}$ vs $\boldsymbol{R 1}$ & $\boldsymbol{P 2}$ vs R2 & tight & $\boldsymbol{P 3}$ vs R1 & $\boldsymbol{P 4}$ vs R2 & redundant 2 \\
\hline LVDd (mm) & $48.7 \pm 8.0$ & $49.7 \pm 8.0$ & ${ }^{*} 0.02$ & 0.21 & $49.1 \pm 7.4$ & 0.28 & 0.37 & $49.3 \pm 7.6$ \\
\%FS (short axis) (\%) & $10.1 \pm 2.9$ & $12.2 \pm 3.7$ & ${ }^{*} 0.011$ & ${ }^{*} 0.011$ & $12.0 \pm 3.9$ & ${ }^{*} 0.026$ & ${ }^{*} 0.010$ & $10.1 \pm 3.5$ \\
Apex-AC (mm) & $56.5 \pm 5.4$ & $57.0 \pm 5.5$ & 0.17 & 0.07 & $56.2 \pm 6.2$ & 0.30 & 0.41 & $56.0 \pm 6.1$ \\
Apex-PC (mm) & $56.8 \pm 7.9$ & $56.6 \pm 7.8$ & 0.31 & 0.07 & $55.9 \pm 8.1$ & $* 0.016$ & ${ }^{*} 0.001$ & $57.2 \pm 8.2$ \\
Apex-Ant. (mm) & $60.0 \pm 6.5$ & $59.0 \pm 6.0$ & 0.11 & 0.08 & $57.9 \pm 5.5$ & ${ }^{*} 0.034$ & ${ }^{*} 0.041$ & $60.1 \pm 6.7$ \\
Apex-Post. (mm) & $56.6 \pm 5.2$ & $56.8 \pm 5.2$ & 0.28 & 0.16 & $56.9 \pm 5.2$ & 0.34 & 0.20 & $57.4 \pm 5.5$ \\
Long axis length & $57.5 \pm 6.1$ & $57.3 \pm 5.9$ & 0.37 & 0.18 & $56.7 \pm 5.9$ & ${ }^{*} 0.041$ & ${ }^{*} 0.015$ & $57.7 \pm 6.4$ \\
\%FS (long axis) (\%) & $8.1 \pm 1.6$ & $9.2 \pm 2.0$ & ${ }^{*} 0.017$ & 0.05 & $9.1 \pm 2.2$ & 0.08 & 0.06 & $7.8 \pm 2.0$ \\
\hline
\end{tabular}

$L V D$ d, left ventricle diastolic dimension; FS, fractional shortning; $A C$, anterior commissure; $P C$, posterior commissure; Ant., mid-anterior annulus; Post., mid-posterior annulus; $R 1$, redundant $1 ; R 2$, redundant 2 . ${ }^{*} P 1$, ${ }^{*} P 3 \leqq 0.05$ vs redundant 1 , t-test for paired observations. ${ }^{*} P 2$, ${ }^{*} P 4 \leqq 0.05$ vs redundant 2 , t-test for paired observations.

Komeda and colleagues ${ }^{31}$ reported in a canine model that the best traction force (after all CT abscission) applied to the PM was $10 \mathrm{~g}$ and that the traction force of $30 \mathrm{~g}$ or higher interfered with LV systolic and diastolic function. Therefore, we used a 15 -g weight as the "adequate" traction force. The dimensions between the midanterior MA and the PM tips after chordal cutting were reduced by the traction. This weight was necessary for the artificial CT to function properly within the appropriate force range of traction.

The results of this study are 2-fold. First, the loadindependent parameters of systolic LV function, such as Ees and PRSW, improved after chordal "translocation." This suggests that secondary CT play an important role in LV systolic function. It is known that Ees reflects pure LV systolic function, whereas PRSW is more or less influenced by diastolic function. In this study, PRSW decreased from "taut" to "tight" with a significant difference. Therefore, a "tight" condition may have possibly disturbed LV diastolic function, although either tau or minimum negative rate of change of the LV pressure did not change between "taut" and "tight." Second, the dimension of the LV long axis was not influenced by the "taut" condition but was reduced by the "tight" condition. Third, the LV long-axis dimension on the anterior MA (1-6) and the posterior commissure (1-5) sides were significantly reduced by the "tight" condition. Although the distance-reduction of the anterior PM side was longer than that of the posterior side, the dimension between the anterior commissure and the apex did not change. However, the dimension between the posterior commissure and the apex was significantly reduced. We think that the apex approached the annulus and shifted toward the posterior commissure side when chordal tension was applied because the ventricular septum was present on the anterior commissure side. Appropriate and effective traction did not affect the geometry of the LV. Excessive traction of the PM such that the apex was shifted impaired the LV function. In this study, inotropic agents were not used during CPB weaning.
If $\mathrm{LV}$ function was strengthened by inotropic agents, the Ees and PRSW values would become too great to observe any effect induced by chordal "translocation."

\section{Study Limitations}

This experiment had several potential limitations.

First, the data were obtained from an acute, open-chest, and open-pericardium setting in normal canine hearts immediately after a complex surgical procedure and cardiac arrest. Therefore, caution must be exercised when extrapolating these findings to human beings with chronic heart disease. Only acute changes in our study were measured. Postoperative LV remodeling cannot be studied in an acute model, and such remodeling may likely have important effects on LV function. For more clinically relevant investigation, it is necessary to study LV geometry and function after chordal "translocation" in a model of chronic heart failure with MR.

Second, because of the reflection of the cables of the sonomicrometry crystal markers and tubes on the annulus in the LA, the MR area was not traced during the serial measurements of "redundant 1," "taut," "tight," and "redundant 2" conditions. However, the color Doppler echocardiography demonstrated absent or trivial (1+) MR after cutting the secondary $\mathrm{CT}$ in all animals.

\section{Conclusions}

"Translocation" of the secondary CT after chordal cutting improved global LV systolic function compared with simple chordal cutting in the failing heart. This study presents further evidence that the secondary CT may physiologically play an important role in valvular-ventricular continuity with respect to LV function.

We thank Tosiya Satoh, PhD, Department of Biostatistics, Kyoto University School of Public Health, for valuable advice on the statistical analysis. 


\section{References}

1. Tibayan FA, Rodriguez F, Zasio MK, Bailey L, Liang D, Daughters GT, et al. Geometric distortions of the mitral valvular-ventricular complex in chronic ischemic mitral regurgitation. Circulation. 2003; 108(suppl II):116-21.

2. Yiu SF, Enriquez-Sarano M, Tribouilloy C, Seward JB, Tajik J. Determinants of the degree of functional mitral regurgitation in patients with systolic left ventricular dysfunction-a quantitative clinical study. Circulation. 2000;102:1400-6.

3. Komeda M, Glasson JR, Bolger AF, Daughters GT, Maclsaac A, Oesterle SN, et al. Geometric determinants of ischemic mitral regurgitation. Circulation. 1997;96(suppl II):128-33.

4. Grigioni F, Enriquez-Sarano M, Zehr KJ, Bailey KR, Tajik AJ. Ischemic mitral regurgitation long-term outcome and prognostic implications with quantitative Doppler assessment. Circulation. 2001;103: 1759-64.

5. Tahta SA, Oury JH, Maxwell JM, Hiro SP, Duran CMG. Outcome after mitral valve repair for functional ischemic mitral regurgitation. J Heart Valve Dis. 2002;11:11-9.

6. Aklog L, Filsoufi F, Flores KQ, Chen RH, Cohn LH, Nathan NS, et al. Does coronary artery bypass grafting alone correct moderate ischemic mitral regurgitation? Circulation. 2001;104(12 suppl I):I68-75.

7. Trichon BH, Glower DD, Shaw LK, Cabell CH, Anstrom KJ, Felker GM, et al. Survival after coronary revascularization, with and without mitral valve surgery, in patients with ischemic mitral regurgitation. Circulation. 2003;108(suppl I):II103-10.

8. Tibayan FA, Rodriguez F, Langer F, Zasio MK, Bailey L, Liang D, et al. Does septal-lateral annular cinching work for chronic ischemic mitral regurgitation? J Thorac Cardiovasc Surg. 2004;127:654-63.

9. Bolling SF, Pagani FD, Deeb GM, Bach DS. Intermediate-term outcome of mitral reconstruction in cardiomyopathy. $J$ Thorac Cardiovasc Surg. 1998;115:381-8.

10. Bolling SF. Mitral reconstruction in cardiomyopathy. $J$ Heart Valve Dis. 2002;11:(suppl I):S26-31.

11. Miller DC. Ischemic mitral regurgitation redux-to repair or to replace? J Thorac Cardiovasc Surg. 2001;122:1059-62.

12. Hung J, Papakostas L, Tahta SA, Hardy BG, Bollen BA, Duran CM, et al. Mechanism of recurrent ischemic mitral regurgitation after annuloplasty: continued LV remodeling as a moving target. Circulation. 2004;110(suppl II):85-90.

13. Matsunaga A, Tahta SA, Duran CMG. Failure of reduction annuloplasty for functional ischemic mitral regurgitation. $J$ Heart Valve Dis. 2004;13:390-8.

14. Al-Radi OO, Austin PC, Tu JV, David TE, Yau TM. Mitral repair versus replacement for ischemic mitral regurgitation. Ann Thorac Surg. 2005;79:1260.

15. Calafiore AM, Di Mauro M, Gallina S, Di Gianmarco G, Iaco AL, Teodori G, et al. Mitral valve surgery for chronic ischemic mitral regurgitation. Ann Thorac Surg. 2004;77:1989-97.

16. Harris KM, Sundt TM III, Aeppli D, Sharma R, Barzilai B. Can late survival of patients with moderate ischemic mitral regurgitation be impacted by intervention on the valve? Ann Thorac Surg. 2002;74:1468-75.

17. Lam BK, Gillinov AM. Importance of moderate ischemic mitral regurgitation. Ann Thorac Surg. 2005;79:462-70.

18. Fayad G, Modine T, Tourneau TL, Al-Ruzzeh S, Ennezat PV, Decoene $\mathrm{C}$, et al. Chordal cutting technique through aortotomy: a new approach to treat chronic ischemic mitral regurgitation. $J$ Thorac Cardiovasc Surg. 2005;129:1173-4.

19. Nielsen SL, Timek TA, Green GR, Dagum P, Daughters GT, Hasenkam JM, et al. Influence of anterior mitral leaflet second-order chordae tendineae on left ventricular systolic function. Circulation. 2003;108: 486-91.

20. Timek TA, Nielsen SL, Green GR, Dagum P, Bolger AF, Daughters $\mathrm{GT}$, et al. Influence of anterior mitral leaflet second-order chordae on leaflet dynamics and valve competence. Ann Thorac Surg. 2001;72: $535-41$.

21. Messas E, Pouzet B, Touchot B, Guerrero JL, Vlahakes GJ, Desnos M, et al. Efficacy of chordal cutting to relieve chronic persistent ischemic mitral regurgitation. Circulation. 2003;108(suppl II):111-5.
22. Messas E, Guerrero JL, Handschumacher MD, Conrad C, Chow CM, Sullivan S, et al. Chordal cutting - a new therapeutic approach for ischemic mitral regurgitation. Circulation. 2001;104:1958-63.

23. Goetz WA, Lim HS, Lansac E, Saber HA, Pekar F, Weber PA, et al. Anterior mitral basal 'stay' chords are essential for left ventricular geometry and function. J Heart Valve Dis. 2005;14:195-203.

24. Rodriguez F, Langer F, Harrington KB, Tibayan FA, Zasio MK, Cheng A, et al. Importance of mitral valve second-order chordae for left ventricular geometry, wall thickening mechanics, and global systolic function. Circulation. 2004;110(suppl II):115-22.

25. Obadia JF, Janier M. Second order anterior mitral leaflets play a role in preventing systolic anterior motion. Ann Thorac Surg. 2002;73: 1689-90; author reply 1690 .

26. Gams E, Hagl S, Schad H, Heimisch W, Mendler N, Sebening F. Importance of the mitral apparatus for left ventricular function: an experimental approach. Eur J Cardiothorac Surg. 1992;6(suppl 1): S17-23; discussion S24.

27. Komeda M, David TE, Rao V, Sun Z, Weisel RD, Burns RJ. Late hemodynamic effects of the preserved papillary muscles during mitral valve replacement. Circulation. 1994;90:190-4.

28. Hennein HA, Swain JA, McIntosh CL, Bonow RO, Stone CD, Clark RE. Comparative assessment of chordal preservation versus chordal resection during mitral valve replacement. J Thorac Cardiovasc Surg. 1990;99:828-37.

29. Rodriguez F, Langer F, Harrington KB, Tibayan FA, Zasio MK, Liang $\mathrm{D}$, et al. Cutting second-order chords does not prevent acute ischemic mitral regurgitation. Circulation. 2004;110(suppl II):91-7.

30. Komeda M. Exploring better methods to preserve the chordae tendineae during mitral valve replacement. Ann Thorac Surg. 1995;60: $1652-8$.

31. Komeda M, DeAnda A Jr, Glasson JR, Daughters GT, Bolger AF, Nikolic SD, et al. Improving methods of chordal sparing mitral valve replacement. Part III: Optimal direction for artificial chordae. J Heart Valve Dis. 1996;5:484-90.

\section{Discussion}

Dr D. Adams (New York, NY). I learned from Dr Carpentier a long time ago about the importance of archways and tension, and how chordae come into the body of the leaflet creating an arch.

I've always thought that perhaps this is to protect the AL, to serve as sort of a protection against it having too much tension in terms of preventing degeneration, not necessarily just to support the ventricle.

In your results, one thing I'm interested in is understanding the direction of force. You say that you put these back into a position to maintain the normal force and try and create normal tension. But in the pathologic ventricle, as the PMs get displaced, I'm curious what direction you would try and reimplant these.

The second question is just a practical one. How would you set the tension clinically?

I think it's an interesting concept and congratulate you. I'm curious if you could tell us the clinical relevance and how you try and use it.

Dr M. Komeda (Kyoto, Japan). I will be answering the questions for Dr Fukuoka.

Dr Adams, thank you for the interesting questions.

About question one, you're right, the direction may change with the dilatation of the LV or dysfunction of the ventricle. In either case, the direction between the papillary tip and the anterior part of the MA is just the same, no matter what the ventricular dimension is. So we believe this method may serve as the proper force direction.

About question two, we briefly mentioned that. We set the tension at $15 \mathrm{~g}$ in the diastolic, and then we clamp the distance. In other words, the end-diastolic tension should be $15 \mathrm{~g}$, which is almost the same as the one we reported from Stanford. When I was 
working at Stanford for Craig Miller, 10 to $15 \mathrm{~g}$ provided the best LV systolic and diastolic function in terms of the valvularventricular continuity of tension.

Dr Adams. The question is, do you think the tension that you're measuring with grams increases as the ventricle dilates? I'm sure that's not a steady state. So in the pathologic ventricle, I doubt that $15 \mathrm{~g}$ would be enough. How would we sort that out?
Dr Komeda. That's an important issue. In the acute phase, if the PM gets a necrosis, or there was secondary remodeling, things are different. But the distance between the papillary tip and the MA is almost constant regardless of heart rate, contractility, and preload/afterload. So that's why we kept the same distance between the papillary tip and the anterior annulus.

Access to The Journal of Thoracic and Cardiovascular Surgery Online is reserved for print subscribers!

Full-text access to The Journal of Thoracic and Cardiovascular Surgery Online is available for all print subscribers. To activate your individual online subscription, please visit The Journal of Thoracic and Cardiovascular Surgery Online, point your browser to http://www.mosby.com/itcvs, follow the prompts to activate your online access, and follow the instructions. To activate your account, you will need your subscriber account number, which you can find on your mailing label (note: the number of digits in your subscriber account number varies from 6 to 10). See the example below in which the subscriber account number has been circled:

\section{Sample mailing label}



Personal subscriptions to The Journal of Thoracic and Cardiovascular Surgery Online are for individual use only and may not be transferred. Use of The Journal of Thoracic and Cardiovascular Surgery Online is subject to agreement to the terms and conditions as indicated online. 